\title{
As Relações Civis-Militares em Portugal: O Longo Processo para o Controle Civil e a Eficácia Militar*
}

\section{Thomas C. Bruneau}

National Security Affairs Department, Naval Postgraduate School (NPS), Monterey, CA.

E-mail: tbruneau@nps.edu

\section{INTRODUÇÃO}

mbora Portugal seja uma nação relativamente pequena da Europa E Ocidental, o país serve como um excelente estudo de caso para a discussão sobre as relações civis-militares na medida em que criou, praticamente do zero, instituições de controle civil e democrático das Forças Armadas, capazes de responder a mudanças no ambiente nacional e internacional. Ademais, construiu estruturas conjuntas de comando e formação profissional para aprimorar simultaneamente o controle civil e a eficácia das Forças Armadas. Portugal foi a primeira das "novas democracias", tendo inaugurado a Terceira Onda de Democratização em 25 de abril de 1974. O regime autoritário português (1928-1974) não foi, em sentido estrito, uma ditadura militar, embora tivesse apoio dos militares; na luta contra três guerras de insurreição na África, entre 1961 e 1974, os contingentes das Forças Armadas elevaram-se a 200 mil homens e chegaram a absorver cerca de metade dos orçamentos governamentais.

Com o golpe de 1974, seguido por dois anos de regime militar dominado por um movimento predominantemente de esquerda, ainda que ra-

* [A tradução do original em inglês "Civil-Military Relations in Portugal: The Long Process to Achieve Civilian Control and Military Effectiveness" é de Vera Pereira.]

DADOS - Revista de Ciências Sociais, Rio de Janeiro, vol. 59, no2, 2016, pp. 427 a 448. 
chado, as Forças Armadas assumiram, de fato e de direito, extensas prerrogativas, que entretanto foram progressivamente reduzidas durante os vinte anos subsequentes de governos civis. No início da década de 1990, a gestão do Ministério da Defesa Nacional foi assumida por um civil, e o controle civil acabou por impregnar todos os aspectos da defesa nacional e das políticas de segurança. Recentemente, a partir de 2009, o Ministério da Defesa Nacional de liderança civil foi ainda mais fortalecido pela investidura de um comando operacional conjunto. Foi criado também um sistema educacional conjunto, com a supervisão civil de programas de instrução profissional em instituições militares.

Nenhum fator isolado explica a trajetória contínua e positiva, se comparada com outros países, das relações civis-militares em Portugal. Neste artigo, argumento que há uma série de fatores causais que nos permitem compreender essas importantes reformas, inclusive a política interna, as relações com a Organização do Tratado do Atlântico Norte (OTAN), a União Europeia e os Estados Unidos, e a escolha atual de tarefas militares - sobretudo em missões de paz e humanitárias. Todos esses fatores combinados resultaram em fortes incentivos para que os responsáveis civis pelas decisões dessem prioridade às Forças Armadas e a soluções inovadoras. No prazo de uma geração, a experiência de Portugal demonstra ter passado por fases distintas em que foram introduzidas reformas no setor de defesa com vistas a um ambiente estratégico mais amplo${ }^{1}$.

O artigo está dividido em três partes, além desta breve introdução. Em um primeiro momento, traçamos um panorama histórico sobre as relações civis-militares em Portugal, começando com a Terceira Onda de Democratização e seguindo, respectivamente, com as primeiras reformas no início dos anos 1980, a consolidação do controle civil na década de 1990 e, finalmente, o cenário pós-11 de Setembro. A segunda parte do texto, por sua vez, busca desenvolver um modelo analítico para compreender as relações civis-militares na atualidade, a partir das noções de controle civil democrático, eficácia e eficiência. Finalmente, dito modelo de análise é aplicado ao caso de Portugal.

\section{UM PANORAMA HISTÓRICO DAS RELAÇÕES CIVIS-MILITARES EM PORTUGAL}

\section{O Início da “Terceira Onda"}

A Terceira Onda de Democratização começou em 25 de abril de 1974, quando o Movimento das Forças Armadas (MFA), formado por cerca 
de 200 oficiais de média e baixa patente, derrubou o governo civil autoritário que estava no poder há quase cinquenta anos (Huntington, 1991). Na luta entre diferentes facções políticas e militares que disputaram o poder durante os dois anos subsequentes, ocorreu finalmente uma peculiar transição para a democracia, na qual as Forças Armadas tiveram um papel muito importante.

A Constituição de 1976 nasceu de um pacto político entre o MFA e os quatro principais partidos políticos, e consagrou juridicamente a continuidade do papel dos militares no Conselho da Revolução (CR), não eleito e exclusivo, o qual detinha a autoridade final sobre as Forças Armadas e a política de defesa. Além disso, o Conselho funcionava como corte constitucional e, nessa condição, decidiu pela inconstitucionalidade de várias leis que tinham sido aprovadas pelo Parlamento, a Assembleia da República (AR). Destarte, se não houve um regime militar em Portugal durante o longo período autoritário, a natureza da transição democrática no país inseriu as Forças Armadas como elemento central do poder político. Os militares também usufruíram de privilégios e poderes, visto que os gabinetes dos governos civis após 1976 eram compostos também de oficiais. Além disso, o presidente escolhido em eleições diretas em 1976, reeleito em 1981, foi o general Ramalho Eanes, que aliou a função de Chefe de Estado à de Chefe do Estado-Maior-General das Forças Armadas (EMGFA), o órgão militar superior do país.

Em suma: o Portugal democrático contemporâneo iniciou-se na Terceira Onda com um amplo componente militar, situação muito diferente da maioria das transições posteriores em outros países, porque nele o movimento partiu fundamentalmente do MFA e não da oposição civil. Desde as primeiras eleições parlamentares de 1976, e até 1987, nenhum partido obteve maioria dos votos, sendo que houve dez governos e cinco eleições gerais nesse período de onze anos. Sob regime semiparlamentarista, com um presidente relativamente poderoso escolhido em eleições diretas, a estabilidade política se manteve enquanto os governos entravam e saíam. Se os governos eram temporários e instáveis, os militares permaneceram estáveis como instituição ao longo deste período de onze anos ${ }^{2}$.

\section{As Primeiras Reformas no Início dos Anos 1980}

No contexto das negociações para ingressar na Comunidade Europeia, que tiveram início em 1978, e com a criação de um Ministério da Defesa

DADOS - Revista de Ciências Sociais, Rio de Janeiro, vol. 59, no 2, 2016 
Nacional (MDN) em 1982, liderado por um político influente, Diogo Freitas do Amaral, do conservador Partido do Centro Democrático Social, foram feitas algumas reformas iniciais. O objetivo era retificar os "entendimentos" derivados das origens do regime democrático em um golpe e dos primeiros anos de radicalismo político e sectarismo militar. Essas reformas trataram, em grande parte, de relações civis-militares. Após complicadas e tensas negociações políticas, a Constituição de 1976 foi revisada em 1982, abolindo-se o Conselho da Revolução. Outros aspectos da Constituição também foram modificados para permitir a entrada dos portugueses na Comunidade Europeia. Nesse mesmo ano, a Lei de Defesa Nacional e das Forças Armadas, elaborada pelo ministro da Defesa Nacional, Diogo Freitas do Amaral, redefiniu a estrutura das Forças Armadas e iniciou a remodelagem da relação com o governo civil eleito. A lei de 1982, constituída de 74 artigos, incluiu todos os aspectos imagináveis de controle civil e das estruturas das Forças Armadas (Freitas do Amaral, 1983).

Deste modo, somente depois de seis anos e do empenho de uma grande quantidade de recursos e de energia política é que foi possível pôr as Forças Armadas sob controle civil formal e democrático (Bruneau e MacLeod, 1986:12-25). O processo de transição democrática em Portugal foi uma experiência singular, como são, aliás, todas as transições políticas. Todavia, o que particularmente o diferenciou foi a inversão da posição relativa das Forças Armadas, que assumiram o poder com o golpe de 25 de abril de 1974 e depois o foram gradualmente cedendo ao longo dos dez anos seguintes.

\section{O Papel do Ministério da Defesa Nacional na Consolidação do Controle Civil}

A consolidação do controle civil levou outra década, desde aproximadamente 1992, e incluiu a experiência de um governo estável liderado pelo Partido Social Democrata (PSD). A partir de 1990, sob a liderança do ministro da Defesa Nacional Fernando Nogueira - a segunda pessoa mais poderosa do governo do PSD -, que promoveu uma ampla campanha pública com a realização de uma série de debates e publicações, os civis finalmente solidificaram seu controle político sobre as Forças Armadas. Em 1993, a legislação básica (as denominadas "leis orgânicas"), definiu os poderes do MDN relativamente às três forças militares e ao chefe do EMGFA, após aprovação pela Assembleia da República. A numerosa e extremamente detalhada legislação transfe- 
riu poderes das Forças Armadas para o Ministério da Defesa civil, aumentou muito a capacidade deste ministério no controle das Forças Armadas e fortaleceu o poder dos chefes de cada força em detrimento do comando do chefe do EMGFA. Portanto, somente em 1994, vinte anos após o golpe, as relações civis-militares adotaram um modelo similar ao de outros países da OTAN e da União Europeia.

É importante examinar com atenção as motivações que levaram às reformas das instituições de defesa e a direção que estas seguiram, pois o grande desafio para realizá-las e, sobretudo, para aumentar a eficácia das Forças Armadas e do setor de segurança não é visto como uma questão relevante na grande maioria dos países. Em geral, nem as elites políticas, nem as Forças Armadas como instituição se interessam pelo assunto ou são incentivadas a enfrentá-lo ${ }^{3}$.

Não é isso, contudo, que acontece em Portugal. As entrevistas que realizei entre 1992 e 1993 em Lisboa me chamaram a atenção para esse fato. Na época, meu tema de estudo eram "as políticas ibéricas de Defesa", o que me levou a examinar as relações entre civis e militares em Portugal e Espanha, pois era preciso determinar em primeiro lugar quem, ou o quê, estava de fato desenvolvendo e executando políticas. Historicamente, o principal vínculo de Portugal com o restante do mundo eram suas colônias, entre as quais o Brasil, e depois as colônias na África (Angola, Guiné-Bissau e Moçambique). A partir de 1975, com o processo de descolonização, Portugal não pôde mais depender das colônias para sustentar esse vínculo. Nessas condições, a OTAN - à qual o país aderiu como membro-fundador, embora estivesse sob um regime político semelhante ao da Espanha, proibida de associar-se representa para Portugal mais do que uma aliança: é um fator-chave para suas relações com os Estados Unidos.

Baseando-me em entrevistas com tomadores de decisões civis, descobri que o problema do acesso dos Estados Unidos à base militar dos Açores sempre foi mais que um meio de obter dinheiro (renda em troca de autorização de acesso à base militar) e de manter o emprego dos habitantes locais. Trata-se de um elemento-chave no envolvimento entre os Estados Unidos e Portugal, visando novamente à diversificação de opções. As reformas institucionais introduzidas nas relações entre civis e militares e na política de defesa de Portugal, bem como na estruturação de suas Forças Armadas para a manutenção de um amplo espectro de papéis e missões, devem ser vistas neste contexto como similares às de outros países democráticos, isto é, possuem o intuito de facilitar o estabele- 
cimento de relações e, logo, um contato mais próximo entre civis e militares (Bruneau e Trinkunas, 2008; Cardoso Reis, 2013). Deve-se notar que os portugueses, com uma força composta de 38 mil oficiais, praças, e contratados, procuram garantir recursos para todo o espectro das capacidades militares do país. Tais relações incluem a defesa do território (com caças F-16, por exemplo), as fragatas Meko usadas nas operações da OTAN, e a ênfase nas ações de paz e nas missões humanitárias sob a égide das Nações Unidas, da própria OTAN e da União Europeia. Sem dúvida, é difícil para um país pequeno e relativamente pobre sustentar essas relações, mas os portugueses têm empenhado grandes esforços para fazê-lo a fim de diversificar suas relações externas.

Vale notar que o Instituto da Defesa Nacional (IDN), financiado pelo MDN e cuja missão principal é o apoio à formulação do pensamento estratégico nacional sobre segurança e defesa, é extremamente atuante, em comparação com outras novas democracias, na promoção das relações civis-militares e no atendimento e deferência às Forças Armadas ${ }^{4}$. Nesse sentido, o IDN contratou pelo menos duas pesquisas de opinião pública para avaliar a extensão do apoio da população às Forças Armadas, a diferentes missões e funções, e para analisar as atitudes populares quanto aos diferentes níveis de segurança nacional e às instituições de defesa. Não tenho conhecimento de pesquisas similares de tamanha envergadura realizadas em outros países, ou pelo menos por um ministério da defesa. A importância dessas pesquisas de opinião e o próprio fato de terem sido encomendadas e financiadas pelo MDN - decorre do apoio generalizado às Forças Armadas e suas atribuições em Portugal, mesmo dentro da reduzida faixa de autonomia do país.

Ao apoiar as pesquisas, o MDN visa assegurar que as inovações institucionais contem com o respaldo popular, fornecendo aos membros das três armas, ao próprio ministério e a outras instituições de defesa e segurança nacional a possibilidade de avaliarem como a opinião pública os vê. Nesta mesma linha, pelo menos uma das motivações para as inovações em curso, que serão descritas na próxima seção, é conservar o apoio popular para as instituições de defesa e segurança nacional (IDN, 1992; Salgado Matos e Bacalhau, 2001).

\section{A Situação Após o 11 de Setembro e uma Avaliação Comparativa dos Ministérios de Defesa: As Prioridades Portuguesas}

Entre as grandes reformas de 1993 e as mais recentes, de início de 2006 até fins de 2014, não houve nenhuma modificação relevante na legisla- 
ção básica ou nas instituições. Cabe notar, porém, que em busca de analisar diferentes opções, o Ministério da Defesa Nacional contratou com o Instituto de Estudos Estratégicos e Internacionais (IEEI) de Lisboa a realização de uma análise comparativa sobre as estruturas, responsabilidades e relações com outras entidades governamentais do Ministério da Defesa de cinco países europeus (Holanda, Grã-Bretanha, Espanha, Bélgica e França). Durante as entrevistas que realizei com pesquisadores envolvidos nesse projeto, fui informado de que o objetivo do estudo era comparar o Ministério da Defesa Nacional português com seus equivalentes na Europa, na intenção de adaptar as instituições portuguesas às mudanças no cenário mundial, particularmente no contexto europeu (Moraes Vaz, nd.)

A análise comparativa das estruturas e responsabilidades dos ministérios traz à baila o aspecto fundamental para a compreensão das motivações determinantes das mudanças recentes nas instituições de segurança e defesa de Portugal. São três essas motivações, duas das quais de natureza histórica e já mencionadas acima. A primeira é o apoio da população portuguesa a essa prioridade histórica; o fato de o MFA ter liderado o golpe que derrubou o regime autoritário e contribuído para a transição para a democracia, aumenta a aprovação popular das Forças Armadas. A segunda, as elites portuguesas estão em sintonia com o que se passa em outros lugares do mundo, sobretudo, mas não exclusivamente na Europa, e desejam assegurar-se de que suas instituições de defesa e segurança nacional sejam tanto quanto possível similares às de outros países do continente. Mais recentemente - e esta é a terceira motivação -, Portugal definiu sua participação em missões de paz e humanitárias, no plano da segurança mundial, como a principal contribuição das Forças Armadas na defesa e segurança nacional. Em síntese, a explicação para um alto grau de inovação e adaptação nas instituições portuguesas não está apenas nos modelos, na influência e nos incentivos oferecidos pela OTAN, Estados Unidos e União Europeia, mas também na percepção por parte da população, dado o golpe e a revolução, da importância crucial das instituições de segurança e defesa nacional.

\section{AS RELAÇÕES CIVIS-MILITARES NA ATUALIDADE: UM MODELO ANALÍTICO}

A fim de analisar as relações civis-militares em Portugal, minha equipe e eu desenvolvemos um modelo analítico baseado em nossa experiência na coordenação de programas e pesquisas sobre esse tipo de relações em cinco continentes. Até recentemente, a grande maioria dos es- 
tudos sobre o tema concentrava-se na questão do controle civil. É fácil entender por que os políticos e os pesquisadores enfocavam esse tipo de relações a partir de uma única perspectiva - a do controle democrático das Forças Armadas. Basta lembrar do dilema clássico resumido numa frase: quem guarda os guardiões? Qualquer força armada forte o suficiente para defender um país também é forte o bastante para derrubar um governo, possivelmente com um golpe de Estado. É este o pressuposto básico da maioria dos estudos sobre as relações civis-militares. Mas priorizar o controle não é suficiente para começar a descrever e analisar essas relações no mundo contemporâneo. Por esse motivo, formulamos um modelo de análise que inclui, além do controle, a eficácia e a eficiência. Além de expandir o foco da análise, buscamos seguir avançando a partir de uma base empírica, em vez de exclusivamente normativa (Bruneau e Matei, 2008; Flisfisch e Robledo, 2012).

\section{Controle Civil}

O controle civil democrático é conceituado empiricamente a partir dos seguintes mecanismos: instituições, supervisão ou vigilância, e normas profissionais. Os mecanismos de controle institucional incluem o fornecimento de direção e orientação para as forças de segurança, as quais podem ser exercidas mediante leis e outros regulamentos bási$\cos$, que dão poder às lideranças e organizações civis providas de equipes profissionais. Das últimas geralmente fazem parte um ministério de defesa para os militares e uma ou mais comissões legislativas que lidam com políticas e orçamentos. A supervisão deve ser exercida pelo líder civil a fim de vigiar os atos das forças de segurança e assegurar que estas sigam efetivamente a direção e as orientações recebidas dos políticos civis. As normas profissionais são institucionalizadas por meio de políticas de recrutamento, formação, treinamento e promoção das Forças Armadas, legalmente aprovadas e transparentes, e em conformidade com os objetivos do líder civil democraticamente eleito. Dessa maneira, os dois mecanismos prévios de controle (instituições e supervisão) são internalizados. Esses três grupos de mecanismos de controle podem ser empregados por civis eleitos democraticamente para exercerem controle sobre as forças de segurança. E, em Portugal, são assim utilizados.

\section{Eficácia}

Cabe reconhecer, de pronto, que é extremamente difícil medir a eficácia. Embora em alguns casos seja possível demonstrar a eficácia do se- 
tor de segurança no cumprimento de papéis e missões, geralmente se pode determiná-la com mais exatidão observando se as instituições de segurança estão preparadas para executar uma ou todas as seis funções que lhes são designadas. As Forças Armadas contemporâneas realizam seis principais papéis ou missões: (1) fazer guerra e estar preparadas para elas; (2) lutar e estar preparadas para guerras internas; (3) contraterrorismo; (4) dar apoio a forças policiais no combate ao crime; (5) realizar missões de paz e humanitárias; (6) dar apoio aos líderes civis em ocorrências de desastres naturais.

O combate efetivo na guerra é o único papel que pode ter referências óbvias de sucesso, e para o qual é possível avaliar empiricamente, em certo grau, a preparação das forças militares para a guerra tomando por base os exercícios prévios. Contudo, descobrir medidas realistas para outros papéis é muito difícil. Mesmo na guerra, quando os países se preparam para se defenderem ou aos aliados contra inimigos externos, o maior indicador de sucesso provavelmente será evitar o combate armado, quer isso se deva à percepção de que os defensores detêm uma força irresistível, ao êxito no emprego de recursos diplomáticos, ou à adesão de um agressor numa aliança que atenua ambições ou queixas.

A Guerra Fria é um bom exemplo da dificuldade de comprovar a eficácia. Sabe-se que o conflito jamais se tornou abertamente militar entre os Estados Unidos e a União Soviética em virtude da dissuasão mútua representada pela existência dos arsenais militares de ambos os lados. A eficácia no desempenho de outros papéis e missões é muito pouco transparente e difícil de medir. As guerras internas possuem causas históricas profundas de natureza política, econômica e social, que não podem ser resolvidas pelo puro e simples emprego da força das armas. A luta tende a arrastar-se e é quase impossível para um lado ou outro declarar-se vitorioso. $\mathrm{O}$ combate ao terrorismo no plano mundial, que é diferente do conflito interno no sentido de que o terrorismo é uma tática e não há um local definido a defender ou derrotar, como um Estado, pode ser considerado bem-sucedido quando não ocorrem ataques. Mas é impossível saber se ataques não ocorreram devido à eficácia das medidas de segurança ou porque os terroristas não quiseram atacar. Tampouco há um momento exato em que se possa dizer com certeza que o terrorismo foi derrotado. A luta contra o crime é permanente, assim como a prestação de assistência humanitária. Nem os criminosos, nem os desastres naturais haverão de desaparecer; são desafios que devem ser antecipados, prevenidos e mitigados com o objetivo de 
manter dentro de limites aceitáveis os crimes, a perda de vidas e os danos ao patrimônio. Com relação às operações de manutenção da paz, o problema é o mesmo. Se os conflitos de fundo se devem a questões religiosas, étnicas ou políticas, e requerem a intervenção de forças de segurança estrangeiras, a presença das tropas não resolverá por si as causas fundamentais, mas pode oferecer alguma estabilidade, separar os antagonistas e abrir espaço a negociações.

Os estudiosos desta matéria precisam, portanto, conhecer em profundidade os fatores necessários à eficácia das medidas de segurança, à capacidade de medi-los e à explicação do sucesso ou fracasso. Nessas circunstâncias, e tomando por base dados comparativos, propomos três requisitos básicos para que as forças de segurança sejam eficazes no cumprimento dos seis papéis e missões já mencionados. Primeiro, deve haver um plano, que pode ser denominado de estratégia ou doutrina. Segundo, deve haver estruturas e processos para a formulação dos planos e principalmente para sua execução. Entre estes, ministérios de defesa e comandos conjuntos que facilitem a cooperação entre civis e militares. Terceiro, o país deve comprometer recursos, fundamentalmente dinheiro e pessoal, para assegurar que disponha de um montante suficiente de equipamentos, forças bem treinadas e outros ativos para dar execução aos papéis e missões designados. Na falta de qualquer desses três componentes, fica difícil imaginar como um país poderia cumprir adequadamente suas missões.

\section{Eficiência}

Eficiência no uso de recursos é a capacidade das Forças Armadas de cumprir os papéis e missões que lhes são designados ao melhor custo possível. Vários problemas complicam a possibilidade de medir a eficiência no setor de segurança, entre eles, a diversidade de funções e missões; a dificuldade de estabelecer medidas de eficiência para cada função isolada, quanto mais para uma combinação delas; além dos desafios metodológicos inerentes à mensuração da eficiência. Desse modo, a eficiência representa na maioria dos casos uma "pista falsa" no campo da segurança, pois requer um grande número de pressupostos não definidos, especialmente no que diz respeito à economia da defesa. Apesar dessas dificuldades, há necessidade de instituições para alocar e controlar a aplicação de recursos como um elemento da responsabilização e da transparência democrática. 
Antes de passar à discussão de como medir a eficiência, é preciso deixar claro a distinção conceitual entre eficácia e eficiência. A literatura sobre teoria das organizações, transições políticas e economia da defesa mostra que os conceitos de eficácia, eficiência, custo-eficiente e similares são muitas vezes fundidos e usados de modo incongruente, até intercambiáveis. De modo geral, pode-se dizer que eficácia é a capacidade de executar políticas e obter os resultados esperados, enquanto eficiência - um conceito fortemente associado à física, à economia e à teoria organizacional - refere-se a obter o máximo resultado possível de um recurso alocado. Em outras palavras, a eficiência na utilização de recursos diz respeito à capacidade de realizar as tarefas e missões designadas a um custo ótimo.

O que se pode medir na área de segurança são dados objetivos (hard data), tais como o número de tanques ou aviões produzidos, o número de soldados treinados ou equipados a um determinado custo. No entanto, esses indicadores são no mínimo limitados e provavelmente enganosos quando se trata de mensurar a eficiência da segurança, mas os políticos os usam para tomar decisões, ou com mais frequência, para racionalizá-las.

Mesmo com a rejeição de metodologias pseudocientíficas para a obtenção de números exatos sobre segurança e defesa nacional, a utilização de fundos públicos numa democracia impõe às agências governamentais a realização de avaliações sistemáticas dos custos e resultados dos programas executados. Uma pesquisa recente conduzida por mim nos Estados Unidos revelou que há mecanismos institucionais bastante amplos e complexos para obter avaliações precisas (Bruneau, 2011). Entre estes temos, no âmbito do Congresso, o Government Accountability Office (GAO), o Congressional Budget Office, Congressional Research Service, órgãos especiais de auditoria, como o Special Inspector General for Iraq Reconstruction, Special Inspector General for Afghan Reconstruction, várias comissões parlamentares e o Committee on Oversight and Government Reform. No âmbito do Executivo, há várias inspetorias gerais e o Office of Management and Budget. Há uma extensa gama de mecanismos de supervisão e vigilância incumbidos não só de examinar a utilização de recursos públicos, como também de avaliar o êxito do governo na realização de metas. $\mathrm{O}$ mais importante desses instrumentos é o GAO, o órgão supremo de auditoria do governo dos Estados Unidos. 


\section{APLICAÇÃO DO MODELO DE ANÁLISE AO CASO DE PORTUGAL}

\section{Controle Civil Democrático}

As reformas de 2006 no Ministério da Defesa Nacional deram início à implantação da estrutura operacional das Forças Armadas e da formação militar conjunta. Sob a liderança do ministro da Defesa, Nuno Severiano Teixeira, entre julho de 2006 e julho de 2009, procedeu-se à modernização do ministério, que saiu fortalecido com novos instrumentos de controle e supervisão e com a recriação de uma estrutura de comando operacional conjunta (EMGFA). O parlamento aprovou três novas leis orgânicas em 2009 relacionadas com as novas estruturas do Ministério da Defesa Nacional e do EMGFA. Em entrevista com este autor, realizada em 11 de março de 2010, o ministro explicou as razões do novo pacote de leis. Primeira, com as ameaças e desafios que se seguiram aos eventos do 11 de Setembro de 2001, havia necessidade de introduzir novos papéis e missões para as Forças Armadas. Segunda razão: Portugal, então membro de toda a arquitetura econômica, política e de segurança e defesa europeia, precisava mudar seu arcabouço jurídico interno a fim de adaptar-se às novas circunstâncias externas (Severiano Teixeira, 2009). As mudanças mais importantes eram: (1) prover uma base jurídica que autorizasse as Forças Armadas a cooperar legalmente com atores de segurança doméstica, inclusive com a Guarda Nacional Republicana e com a Polícia Judiciária; (2) esclarecer e detalhar explicitamente os poderes das diferentes instituições de governo - parlamento, governo e presidência - quanto à segurança nacional e defesa. Nesse processo, aumentaram-se os poderes do MDN. Em suma, houve um fortalecimento do mecanismo institucional de controle.

Mais recentemente, em fins de 2014, todos os aspectos mencionados do controle civil foram definidos e elaborados numa série de leis orgânicas que modificaram a legislação orgânica já existente, de 2009. A Lei Orgânica no 5/2014, de 29 de agosto de 2014, definiu mais uma vez a primazia do MDN. Por exemplo, o artigo 20, inciso 1, declara: “O Ministério da Defesa Nacional é o departamento governamental que tem por missão preparar e executar a política de defesa nacional e das Forças Armadas, bem como assegurar e fiscalizar a administração das Forças Armadas e dos serviços e organismos nele integrados". Em nova entrevista com Nuno Severiano Teixeira, realizada em 10 de fevereiro de 2015, o entrevistado - hoje vice-reitor da Universidade Nova 
de Lisboa, mas ainda muito envolvido com questões de segurança e defesa nacional - deu especial ênfase ao controle dos orçamentos. Este foi um tema usual em outras entrevistas recentes: que a necessidade de economizar e racionalizar todos os custos acentuou fortemente o controle dos ministérios da Defesa e das Finanças, ambos sob gestão civil.

Além do MDN, os entrevistados ressaltaram que o Ministério das Finanças é obrigado por lei a revisar e aprovar recursos para a aquisição e modernização de equipamentos, e inclusive de fundos para os cadetes das academias militares. A Assembleia da República também atua na fiscalização. O presidente da Comissão de Defesa, José de Matos Correia, destacou que, apesar da presença de cinco partidos, criou-se um consenso de que a Comissão é um protagonista ativo nas questões de segurança nacional e defesa. Quanto à fiscalização, o presidente da Comissão observou que, por lei, o ministro da Defesa Nacional deve comparecer às reuniões no mínimo quatro vezes por ano, mas que geralmente ele aparece com mais frequência, inclusive quando a Comissão discute sobre questões importantes, como a Lei de Programação Militar ou sobre o estado das negociações com os Estados Unidos a respeito da base aérea de Lajes no arquipélago dos Açores. A Comissão também realiza investigações acerca de problemas específicos, na forma de comissões de inquérito. Em síntese, a fiscalização e supervisão são conduzidas pelo Ministério da Defesa Nacional, pelo Ministério das Finanças e pela Comissão de Defesa na Assembleia da República.

Finalmente, cabe mencionar a educação profissional militar como outro pilar do controle civil democrático. Neste campo, implementou-se uma reforma do sistema de educação profissional militar (EPM), como parte de uma reforma educacional mais ampla do ensino superior em âmbito europeu, incentivada pelo chamado "processo de Bolonha", que tornou a formação profissional militar equivalente à educação civil. Houve, assim, uma transformação da estrutura institucional da educação militar em Portugal, com a redução de três escolas separadas para cada uma das três armas a uma academia para cada uma e mais uma escola superior conjunta. Em consequência, foi eliminado um nível educacional entre as academias, que ainda são três, e a Escola de Guerra. Havia antes um nível técnico, com três escolas separadas, o qual foi eliminado. Assim, em vez de nove instituições de educação militar separadas, agora existem quatro, com o Instituto de Estudos Superiores Militares (IESM), fundado em setembro de 2005, que assumiu o papel de ápice do sistema de formação e mantém uma variedade 
de cursos para oficiais de todas as patentes. Vale notar que o IESM, rebatizado agora como Instituto Universitário Militar, mantém acordos de cooperação não só com instituições europeias e estadunidenses, quanto com Angola e Moçambique ${ }^{5}$. Existem planos para reduzir as academias separadas para cada uma das armas de três para uma. Haveria, portanto, uma academia militar conjunta e uma única escola de guerra.

Outra instituição civil de controle, semelhante pelo menos à dos Estados Unidos e do Chile, é o requisito de que todos os graus acadêmicos sejam atribuídos por uma Agência de Avaliação de Ensino Superior, sob o auspício do Ministério da Educação. É este que, em última instância, decide, e o ensino militar tem de adequar-se. Trata-se de um mecanismo relativamente novo em Portugal, posto em prática nos últimos cinco anos.

\section{Eficácia Militar}

Em abril de 2013, o governo de Portugal publicou o Conceito Estratégico de Defesa Nacional, documento que define as prioridades do Estado em matéria de defesa e substitui o anterior que estava em vigor desde 2003. Estruturado em sete capítulos, e com um total de cinquenta páginas, é abrangente, prático e objetivo, e deixa bastante claro que qualquer estratégia de defesa nacional deve estar integrada a uma estratégia mais geral de governo. Antes de abordar as Forças Armadas, o documento ressalta que a diplomacia deve ser prioritária. Em seguida, destaca o principal objetivo das forças militares que é o de "consolidar Portugal em sua posição de coproductor de segurança internacional". E declara ainda que "os meios militares são um componente fundamental da segurança do Estado e um elemento de projeção do prestígio internacional de Portugal" (Duarte, 2014:63-89). Os entrevistados acentuaram que houve um longo e difícil processo de elaboração até a publicação do documento, e que envolveu a participação de vários especialistas e de apresentações públicas em todo o país. O documento final foi discutido na Assembleia da República e aprovado pelo primeiro-ministro e pelo Conselho de Ministros em 21 de março de 2013 (IDN, 2013:511).

As leis básicas do MDN retirou poderes do Comandante do EMGFA e limitou seu papel institucional a situações de guerra e estados de sítio ou de emergência. Essas situações são raras, mas decisões sobre o 
envio de tropas ao estrangeiro são bastante comuns, geralmente para missões de paz. De acordo com a nova legislação, de 2003, o Chefe do EMGFA tinha poderes explícitos tanto na guerra quanto na paz. A lei de setembro de 2014 amplia esses poderes. Agora, tudo o que é operacional deve ser feito pelo Chefe do EMGFA. Antes das leis mais recentes, as missões dependiam principalmente do comando de cada uma das armas. Mas chegar à atual situação não foi fácil, porque os comandos de cada uma das três armas não estavam dispostos a ceder poder. Antes de setembro de 2014, o comandante em chefe do Estado Maior era apenas primus inter pares, isto é, o primeiro entre iguais. O comandante-em-chefe continua a ter comando operacional quando tropas portuguesas são enviadas ao exterior, e a lei de 2014 reforçou seus poderes. Deve-se notar que todos os entrevistados ressaltaram que o Chefe do EMGFA presta contas ao Ministério da Defesa civil. Na verdade, a Lei Orgânica no 5/2014, de 29 de agosto de 2014, diz em seu artigo 23, inciso 2, que o "Chefe do Estado Maior das Forças Armadas depende diretamente do Ministro da Defesa Nacional nos termos das competências previstas na lei".

Já no tocante aos recursos, de acordo com a base de dados de despesas militares do Instituto Internacional de Pesquisas para a Paz de Estocolmo, Portugal investiu 2,1\% do seu PIB na Defesa em 2010 e 2,2\% em 2013. Usando a mesma base de dados, os países da Europa Meridional apresentaram decréscimos: na Grécia houve uma queda de 2,7\% em 2010 para 2,4\% em 2013; na Itália, de 1,8\% para 1,6\% no mesmo período, e na Espanha de 1,1\% para 0,9\%. Dados recentes de Portugal, extraídos do Jane's Information Group dizem que houve investimentos de 1,18\% do PIB em 2014 (SIPRI, 2015; Jane's, 2015). Uns 65\% desse total foram destinados a despesas de pessoal. O decréscimo não surpreende se levarmos em conta a grave crise econômica pela qual o país passava nesse período, sob a tutela financeira e econômica da "troika" da União Europeia, do Banco Europeu de Investimento e do Fundo Monetário Internacional. As atividades predominantes das Forças Armadas portuguesas são as de manutenção da paz e missões humanitárias no exterior (Carreiras, 2014), conduzidas sob a égide da ONU, da OTAN e da União Europeia. Somente a ONU reembolsa o país, e segundo informam nossos entrevistados, em cerca de $60 \%$.

Dessa maneira, as graves limitações orçamentárias geram sérias consequências. Segundo Nuno Severiano Teixeira, há três consequências principais (Severiano Teixeira e Santos Pinto, 2014): primeira, a dimi- 
nuição do contingente de militares, que antes era de 47 mil, caiu para 38 mil e deve reduzir-se ainda mais, para 30 mil; segunda, a suspensão da modernização, atingindo inclusive os helicópteros e os navios logísticos; e a suspensão da Lei de Programação Militar. Terceira, há uma redução no número de missões internacionais. Se Portugal contava com aproximadamente 822 soldados comprometidos com essas atividades em 2006, em 2012 baixaram para 468 e, no fim de fevereiro de 2015, eram cerca de 263 (EMGFA, 2015). Note-se que esses 263 oficiais, em consonância com a política de diversificação do portfólio, estavam engajados em oito missões, três da OTAN, duas da ONU e três da União Europeia.

\section{Eficiência}

Outrossim, todos os entrevistados chamaram a atenção para o poder do Tribunal de Contas (TC) sobre todas as contas públicas. Por exemplo, não se podem fechar contas até que o Tribunal conclua sua análise. O TC também realiza auditorias a partir de determinado limiar de gastos e em determinados assuntos, e as Forças Armadas não são imunes a essas auditorias. Apesar de não fazer parte do Legislativo, como nos Estados Unidos, mas do Judiciário, o presidente do Tribunal de Contas presta depoimento à Assembleia da República, quando solicitado.

\section{CONCLUSÕES}

As conclusões desse estudo de caso das relações entre civis e militares em Portugal são diretamente relevantes para outros países e, ademais, apresentam aspectos singulares. De modo geral, sua relevância está em mostrar que custou muito tempo, vinte anos, para que o controle civil democrático se consolidasse por intermédio do Ministério da Defesa Nacional, e mais uma nova década para que a eficácia fosse enfatizada com a criação da estrutura conjunta de comando operacional e se desse início à educação profissional militar conjunta. Outro ponto importante é que as primeiras reformas somente foram possíveis quando o ambiente político, especialmente a estabilidade sob o governo de um partido, mostrou-se favorável. As conclusões são singulares porque para boa parte do mundo, mas não para o programa de Parceria para a Paz, para a OTAN e para os países da União Europeia, pois, além da estabilidade política interna, militares e civis portugueses são diretamente influenciados por atores externos. Em cada uma das principais reformas, evidencia-se a participação desses atores externos no treina- 
mento, nas vendas e subsídios, e nas reformas educacionais. Contudo - e esta é a principal descoberta deste estudo - as reformas são introduzidas com base nas percepções e prioridades dos próprios portugueses. Não há dúvida de que os civis democraticamente eleitos estão no comando das Forças Armadas por intermédio do Ministério da Defesa Nacional. O Estado-Maior-General das Forças Armadas e a formação profissional militar conjunta estão hoje implantados e apoiam a eficácia das ações das Forças Armadas. Embora a situação geral das relações civis-militares em Portugal seja hoje extremamente positiva, o país - como tantos outros da zona do Euro - continua sofrendo os efeitos de uma crise econômica muito grave, com óbvias consequências para a segurança nacional e a defesa. Independentemente dos próximos passos, o longo processo português para o controle civil e a eficácia militar servirá como base para qualquer política futura neste campo.

(Recebido para publicação em maio de 2015)

(Reapresentado em novembro de 2015)

(Aprovado para publicação em fevereiro de 2016) 


\section{NOTAS}

1. Presenciei pessoalmente os acontecimentos do dia 25 de abril de 1974, pois estava em Portugal e tenho uma boa recordação dos fatos. Dessa época para cá, desenvolvi extenso trabalho de pesquisa (que incluiu nove meses de licença sabática, em 1992) sobre política e relações civis-militares nesse país. A adoção de uma abordagem comparativa confere a Portugal uma perspectiva mais impactante, embora seja comum na maioria das novas democracias a ênfase no controle civil. Recentemente, de 8 a 12 de fevereiro de 2015, entrevistei formuladores de políticas públicas acerca de questões militares e de defesa nacional. Entre estes, o professor Nuno Severiano Teixeira, ex-ministro da Defesa, no dia 10 de fevereiro, o general Ramalho Eanes, ex-presidente e Comandante Chefe do Estado Maior das Forças Armadas, José de Matos Correia, presidente da Comissão de Defesa (em 11 de fevereiro) na Assembleia da República, e, finalmente, Vitor Viana, diretor do Instituto de Defesa Nacional (em 11 de fevereiro).

2. Na entrevista do dia 10 de fevereiro de 2015, o general Ramalho Eanes destacou a importância do Conselho da Revolução ao permitir que os militares e os partidos políticos "resolvessem os problemas" do período revolucionário de 1974 a 1976.

3. Os civis não se interessam porque, como se costuma dizer, "defesa não dá voto", e as Forças Armadas também não se interessam porque na maioria das novas democracias, eles não fazem muita coisa mesmo e não querem chamar a atenção para esse fato. Embora eu tenha divergências acadêmicas com David Pion-Berlin no que diz respeito ao papel das Forças Armadas em alguns países da América Latina, creio que Pion-Berlin está certo, em geral, quando afirma que os militares da região “(...) ocupam posições de retaguarda à espera de um chamamento eventual para ajudar outras forças" (Pion-Berlin, 2005:24). Em Bruneau (2013), pode-se encontrar também o debate e os dados a respeito de quatro países sul-americanos.

4. Fiz visitas frequentes ao IDN para entrevistar o diretor e outros civis e militares e para apresentar seminários e conferências. Em comparação com outras novas democracias, o nível de atividade de funcionários civis e militares do IDN é extremamente alto.

5. Visitei o Instituto de Estudos Superiores Militares em 8 de março de 2010, tendo recebido informações e publicações acerca dos programas da entidade. 


\section{As Relações Civis-Militares em Portugal}

\section{REFERÊNCIAS BIBLIOGRÁFICAS}

BRUNEAU, Thomas. (1997), "Portugal's Defense Structures and NATO", in T.-D. Young (ed.), Command in NATO after the Cold War: Alliance, National, and Multinational Considerations. Carlisle Barracks, Strategic Studies Institute, Army War College, pp. 171-188.

(2011), Patriots for Profit: Contractors and the Military in U.S. National Security. Stanford, Stanford University Press.

. (2013), "Civilians and the Military in Latin America: The Absence of Incentives". Latin American Politics and Society, vol. 55, no 4, pp. 143-160.

BRUNEAU, Thomas; MACLEOD, Alex. (1986), Politics in Contemporary Portugal: Parties and the Consolidation of Democracy. Boulder, Lynne Rienner Publishers.

BRUNEAU, Thomas; MATEI, Florina Cristiana. (2008), “Towards a New Conceptualization of Democratization and Civil-Military Relations". Democratization, vol.15, no 5, pp. 909-929.

BRUNEAU, Thomas; TRINKUNAS, Harold. (2008), "Global Trends and Their Impact on Civil-Military Relations", in T. Bruneau; H. Trinkunas (eds.), Global Politics of Defense Reform. New York, Palgrave Publishers.

CARREIRAS, Helena. (2014), “The Sociological Dimension of External Military Interventions: The Portuguese Military Abroad". Portuguese Journal of Social Science vol. 13, no 2, pp. 129-149.

DUARTE, António Paulo. (2014), “A Estratégia Nacional de Defesa do Brasil e o Conceito Estratégico de Defesa Nacional de Portugal: Comparação de Duas Estratégias Nacionais de Segurança e Defesa". Nação e Defesa, no 138, pp. 63-89.

ESTADO-MAIOR GENERAL DAS FORÇAS ARMADAS. Disponível em http://www.emgfa.pt/pt/operacoes/mapa. Acessado em 23 de fevereiro de 2015.

FLISFISCH, Angel; ROBLEDO, Marcos. (2012), Gobernabilidad Democrática de la Defensa en Chile: Un Índice para el Periodo 1990-2010. Santiago, Programa de las Naciones Unidas para el Desarrollo.

FREITAS DO AMARAL, Diogo. (1983), A Lei de Defesa Nacional e das Forças Armadas. Coimbra, Coimbra Editora Limitada.

HUNTINGTON, Samuel. (1991), The Third Wave: Democratization in the Late Twentieth Century. Norman, University of Oklahoma Press.

IDN (INSTITUTO DA DEFESA NACIONAL). (1992), "A Nação e as Questões de Segurança e Defesa: Inquérito à Opinião Pública”. Nação e Defesa, Lisboa.

. (2013), Conceito Estratégico de Defesa Nacional 2013: Contributos e Debate Público. Lisboa, Imprensa Nacional/Casa da Moeda/Instituto da Defesa Nacional.

JANE'S DEFENCE BUDGETS. Disponível em http:/ / www.janes.com/defence. Acessado em 24 de fevereiro de 2015.

MATOS, Luís Salgado de. (1997), “As Forças Armadas Portuguesas como Elemento de um 'Estado de Ordens'”. Análise Social, vol. XXXII, no 2, pp. 405-418.

DADOS - Revista de Ciências Sociais, Rio de Janeiro, vol. 59, no 2, 2016 
; BACALHAU, Mário. (2001), As Forças Armadas em Tempo de Mudança: Uma Sondagem à Opinião Pública nas Vésperas do Século XXI. Lisboa, Edições Cosmos.

MEDEIROS FERREIRA, José. (1989), “Um Corpo perante o Estado: Militares e Instituições Políticas", in M. B. Coelho (org.), Portugal: O Sistema Político e Constitucional, 1974-87, Lisboa, Instituto de Ciências Sociais.

MORAES VAZ, Maria do Rosário de. (2003), Adaptação e Mudança nos Ministérios de Defesa Europeus: Aspectos Orgânicos, Políticos e Institucionais. Lisboa, Instituto de Estudos Estratégicos.

PION-BERLIN, David. (2005), "Political Management of the Military in Latin America", in Military Review, vol. 85, no 1, pp.19-31.

SEVERIANO TEIXEIRA, Nuno. (2009), Contribuição para uma Política de Defesa: Julho de 2006 a Julho de 2009. Lisboa, Ministério de Defesa Nacional.

. (2013), "Reforma do Estado e Reforma das Forças Armadas". Relações Internacionais, no 37, pp. 5-14.

; PINTO, Ana Santos. (2014), "European Defence in Time of Austerity: The Case of Southern Europe". RSCAS Policy Paper 2014/08, European University Institute; Robert Schuman Centre for Advanced Studies Global Governance Programme.

REIS, Bruno Cardoso. (2013), "Portugal”, in H. Biehl; B. Giegerich; A. Jonas (eds.), Strategic Cultures in Europe: Security and Defence Policies Across the Continent. Potsdam, Springer VS, pp. 281-291. 


\section{RESUMO}

As Relações Civis-Militares em Portugal: O Longo Processo para o Controle Civil e a Eficácia Militar

O artigo trata das relações entre civis e militares em Portugal usando um quadro analítico baseado em indicadores empíricos relativos a três dimensões: controle democrático por parte de civis, eficácia no desempenho de tarefas e missões, e eficiência. Apesar da crise econômica e da consequente falta de recursos do governo, esta análise se mostra positiva numa perspectiva comparada. Ademais da influência e dos incentivos de organizações internacionais, especificamente da OTAN, da União Europeia e das Nações Unidas, o artigo examina a utilização de políticas de defesa e das Forças Armadas, tanto pelos civis quanto pelos militares, na perseguição de objetivos estratégicos.

Palavras-chave: relações civis-militares; Portugal; controle civil democrático; eficácia militar; eficiência na política de defesa

\section{ABSTRACT \\ Civil-Military Relations in Portugal: The Long Process to Achieve Civilian Control and Military Effectiveness}

Civil-military relations in Portugal are analyzed employing a framework with empirical indicators focusing on the three dimensions of democratic civilian control, effectiveness in roles and missions, and efficiency. Despite the economic crisis, and consequent lack of government resources, this analysis of Portugal is positive in comparative perspective. In addition to the influence and incentives of international organizations, specifically NATO, EU, and the $\mathrm{UN}$, the author emphasizes how civilians and military use defense policy and the armed forces in pursuing strategic goals.

Keywords: civil-military relations; Portugal; democratic civilian control; military effectiveness; efficiency in defense 


\section{RÉSUMÉ}

Les Rapports entre Civils et Militaires au Portugal: Un Long Processus de Définition du Contrôle Civil et des Compétences Militaires

Les rapports entre civils et militaires au Portugal sont ici analysés dans un cadre basé sur des indicateurs empiriques et ciblant les trois dimensions du contrôle civil et démocratique, de la définition des rôles et des missions, et des compétences. En dépit de la crise économique et du manque à gagner conséquent en termes de ressources publiques, cette analyse du Portugal sous une perspective comparative s'est avérée positive. Outre l'influence et les soutiens d'organisations internationales (et plus spécifiquement de l'OTAN, de l'UE et de l'ONU), l'auteur met en lumière la manière dont civils et militaires utilisent la politique de défense et les forces armées pour poursuivre des objectifs stratégiques.

Mots-clés: rapports civils-militaires; Portugal; contrôle civil et démocratique; compétences militaires; efficacité de la défense

\section{RESUMEN}

Las Relaciones entre Civiles y Militares en Portugal: Un Largo Proceso de Definición del Control Civil y de la Eficacia Militar

El artículo examina las relaciones entre civiles y militares en Portugal utilizando un marco analítico basado en indicadores empíricos relativos a tres dimensiones: el control democrático por parte de los civiles, la eficacia en el desempeño de tareas y misiones, y la eficiencia. A pesar de la crisis económica y de la consecuente falta de recursos del gobierno, esta análisis se muestra positiva a partir de una perspectiva comparativa. Además de la influencia de la OTAN, de la Unión Europea y de Naciones Unidas, el artículo analiza la utilización de políticas de defensa y de las Fuerzas Armadas, tanto por los civiles como por los militares, en la persecución de objetivos estratégicos.

Palabras clave: relaciones civiles-militares; Portugal; control civil democrático; eficacia militar; eficiencia en la política de defensa 